\title{
In vitro propagation and DNA barcode analysis of the endangered Silene schimperiana in Saint Katherine protectorate
}

Heba El-Sayed Ghareb ${ }^{1}$, Shafik Darwish Ibrahim² and Ghada Abd El-Moneim Hegazi ${ }^{*}$ (1)

\begin{abstract}
Background: Anthropogenic activity, climate change, pollution, and exploitation of natural resources are some reasons that cause threatening of plant diversity. Silene schimperiana is an endangered plant species in Egypt and is endemic to the high mountain of Saint Katherine Protected Area in southern Sinai. The purpose of the study was the ex situ conservation of Silene schimperiana through in vitro propagation and DNA barcode analysis.

Results: To develop an efficient ex situ conservation program of the plant, in vitro propagation protocol has been achieved from shoot tip and stem nodal segment explants of in vitro germinated seedlings. Explants were established in vitro on Murashige and Skoog (MS) medium supplemented with $2.89 \mu \mathrm{M}$ gibberellic acid $\left(\mathrm{GA}_{3}\right)$, $1.08 \mu \mathrm{M}$ a-naphthaleneacetic acid (NAA), and $1.16 \mu \mathrm{M}$ kinetin (Kin). The highest number of axillary shoots (9.27) was obtained when they were transferred to MS medium supplemented with $4.48 \mu \mathrm{M}$ 6-benzyl adenine (BA). Hundred percent of multiple axillary shoots were rooted on quarter-strength MS medium supplemented with $4.92 \mu \mathrm{M}$ indole-3-butyric acid (IBA) and $10.75 \mu \mathrm{M}$ NAA. Rooted plants were transferred to pots containing a soil-peat mixture $(1: 2 \mathrm{~V} / \mathrm{V})$ and successfully acclimatized in the greenhouse. Plant identification is a crucial aspect to understand and conserve plant diversity from extinction. DNA barcode analysis of Silene schimperiana was carried out using two chloroplast DNA markers (cpDNA): 1,5-bisphosphate carboxylase/oxygenase large subunit ( $r b c L$ ) and RNA polymerase subunit (rpoC1) and a nuclear ribosome DNA marker (ncDNA), internal transcribed spacer (ITS). Phylogenetic analysis revealed a successful identification of Silene schimperiana on the species and genus levels and supported the inclusion of Silene schimperiana in genus Silene.

Conclusions: In this study, a relevant in vitro propagation method was established to facilitate the recovery of Silene schimperiana, in addition to DNA barcoding of the plant as a tool for effective management and conservation of plant genetic resources.
\end{abstract}

Keywords: Caryophyllaceae, Micropropagation, DNA barcoding, Southern Sinai, Egypt

\footnotetext{
* Correspondence: ghada.hegazi1211@gmail.com

${ }^{1}$ Tissue Culture Unit, Department of Genetic Resources, Desert Research

Center, 1 Mathaf El-Matareya Street, Cairo, El-Matareya 11357, Egypt

Full list of author information is available at the end of the article
}

\section{Springer Open}

(c) The Author(s). 2020 Open Access This article is licensed under a Creative Commons Attribution 4.0 International License, which permits use, sharing, adaptation, distribution and reproduction in any medium or format, as long as you give appropriate credit to the original author(s) and the source, provide a link to the Creative Commons licence, and indicate if changes were made. The images or other third party material in this article are included in the article's Creative Commons licence, unless indicated otherwise in a credit line to the material. If material is not included in the article's Creative Commons licence and your intended use is not permitted by statutory regulation or exceeds the permitted use, you will need to obtain permission directly from the copyright holder. To view a copy of this licence, visit http://creativecommons.org/licenses/by/4.0/. 


\section{Background}

Saint Katherine Protectorate is one of the largest protected areas in Egypt with the highest mountains. It supports surprising biodiversity and a high proportion of endemic and rare plants. The flora of the mountains differs from the other areas, due to its unique geological, morphological, and climatic aspects [1]. The protection and conservation of endemic plant species is a worldwide need; especially under the threat of climate change. Endemic species are the most defenseless, because of their unique evolutionary history and low population estimate [2].

Silene schimperiana Boiss. is a perennial herb, belonging to the largest genus from family Caryophyllaceae. Its Arabic name is Wesbi or Losseiq [3]. The plant is a hemicryptophyte, growing on rocky wadi beds. It is potentially an ornamental plant with attractive white flowers [4] and has economic importance in grazing processes as a pastoral plant [5].

Silene schimperiana is endangered in Egypt and is endemic to the high mountain of Saint Katherine Protected Area in southern Sinai. The plant populations are severely fragmented with a continuing decline in habitat quality [5]. Drought is the major threat affecting the distribution of Silene schimperiana, in addition to climate change. The plant has low viability due to destructive overgrazing, causing loss of reproductive organs. With drought, the effect of overgrazing is more harmful and the wild populations of this species could be in extreme danger in the near future [5]. Ex situ conservation by in vitro propagation and molecular identification are important actions needed to conserve the plant [5].

In vitro propagation of other species of Silene have been achieved previously, such as S. leucophylla [6], S. fetissovii, S. obovata, S. sussamyrica and S. ladyginae [7], Silene cretacea [8], Silene bolanthoides [9] and Silene fabaria subsp. domokina [10].

Identification of rare and endemic plant species is an important base for evolutionary and phytogeographic studies as well as for the determination of conservation priorities [11].

DNA barcoding is a molecular marker-based technique, in which short fragments of DNA from a standardized genome position are utilized. This technique identifies plant species more definite than the traditional taxonomic tools, with unrecognizable plant parts and without requiring taxonomic experience [12, 13]. DNA barcoding has applications in biodiversity monitoring, conservation impact assessment, forensic botany, monitoring illegal trading, etc. Also, DNA is stable and is found in all tissues; therefore, DNA barcoding of medicinal plants can be used for identifying powdered or processed plant materials [14].
Studying the molecular phylogeny of plants depends mainly on the sequencing of the chloroplast genome, because of its simple and stable genetic structure. Universal primers are used for these target sequences amplification, such as 1,5-bisphosphate carboxylase/oxygenase large subunit $(r b c L)$ and RNA polymerase subunit (rpoC1) have been heavily relied upon for the development of markers for plant DNA barcoding [15]. The Consortium for the Barcode of Life (CBOL) [16] plant working group evaluated the efficacy of the chloroplast DNA marker (cpDNA), rbcL among the recommended markers. The $r b c L$ gene is the most published plastid barcode due to its high amplification success rate and is considered a core DNA barcoding marker for the determination of plant diversity $[13,17,18]$. Besides, the nuclear ribosome DNA marker (ncDNA), internal transcribed spacer (ITS) and cpDNA, rpoC1 were frequently evaluated as plant barcodes [12, 19]. DNA barcoding markers are universal and the choice of the correct loci is challenging [20].

To date, there has been no published researches on the in vitro culture or DNA barcoding of Silene schimperiana and therefore, the aim of the present study was the ex situ conservation of Silene schimperiana as an endangered plant, endemic to Saint Katherine, through in vitro propagation and identification by DNA barcode analysis using two cpDNA genes: $r p o C 1$ and $r b c L$ and a ncDNA gene, ITS.

\section{Methods}

\section{Plant material}

Leaf specimens and seeds of Silene schimperiana were collected from shrubs grown in Gebel Tennia, Saint Katherine, South of Sinai E: 33.90090 N: 28.57364 Alt: 1810 (Figs. 1 and 2). Identification of plant was carried out by Dr. Omran Ghaly, Head of Plant Taxonomy Unit, Desert Research Center, Egypt, given the voucher number CAIH-1003-R and voucher specimens were deposited in the Herbarium of Desert Research Center (CAIH).

\section{In vitro experiments \\ In vitro germination}

Collected seeds of Silene schimperiana were washed with running tap water and detergent, then surface sterilized by soaking in commercial bleach containing sodium hypochlorite $(5.25 \%)$ under laminar airflow cabinet (Holten LaminAir HVR 2448, USA), at different concentrations $(0.5,1.0$, and $1.5 \%$ sodium hypochlorite solution). After $15 \mathrm{~min}$, seeds were taken out and thoroughly washed thrice with sterilized distilled water. Seeds were cultured on half-strength Murashige and Skoog (1/2 MS) [21] medium (Duchefa, Haarlem, the Netherlands) supplemented with $3 \%(\mathrm{w} / \mathrm{v})$ sucrose and $5.77 \mu \mathrm{M}$ 


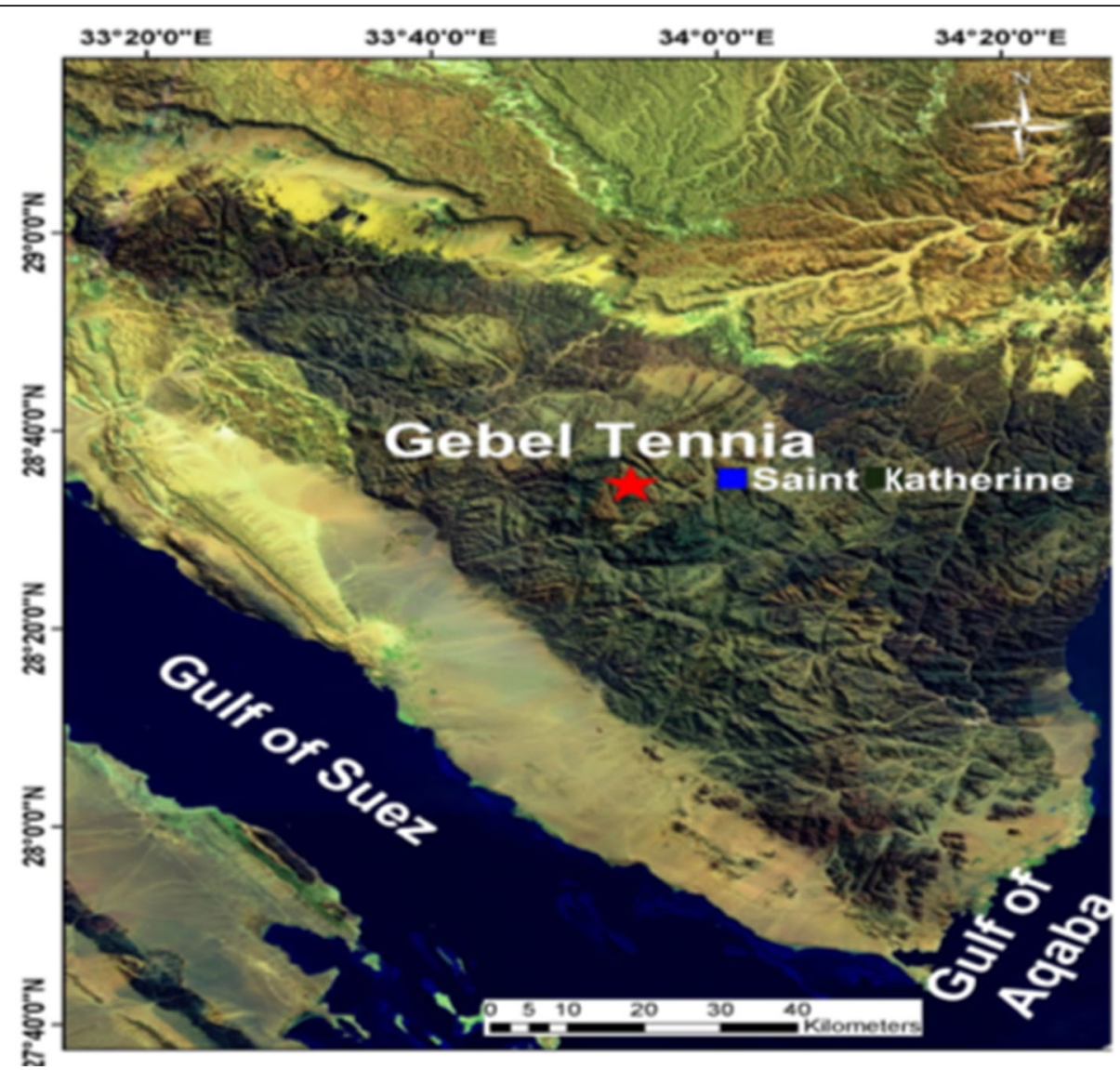

Fig. 1 A map showing the location of Gebel Tennia, the collection site of Silene schimperiana

gibberellic acid ( $\mathrm{GA}_{3}$; Sigma Cell Culture, min. 90\%, St. Louis, USA) (0.45 $\mu \mathrm{m}$ filter sterilized) for germination. The $\mathrm{pH}$ was adjusted to $5.7 \pm 0.1$, then medium was gelled with $0.3 \%(\mathrm{w} / \mathrm{v})$ phytagel (Duchefa, Haarlem, the Netherlands) before autoclaving at a pressure of $1.06 \mathrm{~kg} /$ $\mathrm{cm}$, and $121^{\circ} \mathrm{C}$ for $15 \mathrm{~min}$ (Harvey Sterilemax autoclave, Thermo Scientific, USA). Cultures were incubated under cool fluorescent tubes at day-night regime of 16-h photoperiod with the light intensity of 2500-3000 lux (F140t9d/38, Toshiba) at a constant temperature of $25 \pm$ $2{ }^{\circ} \mathrm{C}$ and $60-70 \%$ relative humidity. The produced seedlings were cut into shoot tips and stem nodal segments and were used as explants.

\section{In vitro propagation}

Establishment stage Shoot tips and stem nodal segment explants of seedlings were transferred to MS medium supplemented with $3 \%(\mathrm{w} / \mathrm{v})$ sucrose and $0.3 \%(\mathrm{w} / \mathrm{v})$ phytagel and $2.89 \mu \mathrm{M} \quad \mathrm{GA}_{3}, 1.08 \mu \mathrm{M} \quad \alpha$-naphthalene acetic acid (NAA) and different concentrations of 6benzyl adenine (BA) of $1.11,2.22$, and $4.48 \mu \mathrm{M}$ or kinetin (Kin) of 1.16, 2.33, and $4.65 \mu \mathrm{M}$ (Sigma Cell Culture, min. 90\%, St. Louis, USA). MS medium without plant growth regulators (PGRs) served as a control. The $\mathrm{pH}$ of the medium was adjusted to $5.7 \pm 0.1$ and autoclaved at a pressure of $1.06 \mathrm{~kg} / \mathrm{cm}$ and $121^{\circ} \mathrm{C}$ for $15 \mathrm{~min}$. Cultures were incubated at $25 \pm 1{ }^{\circ} \mathrm{C}$ at a photoperiod of $16 / 8 \mathrm{~h}$ light/darkness under cool white fluorescent tubes of 2500-3000 lux. The survival and growth percentage (\%), the mean number and length $(\mathrm{cm})$ of axillary shoots/explant were recorded after 3 weeks of culture.

Multiplication stage The in vitro produced axillary shoots were transferred to MS medium supplemented with $3 \%(\mathrm{w} / \mathrm{v})$ sucrose and $0.3 \%(\mathrm{w} / \mathrm{v})$ phytagel and different concentrations of cytokinins (Sigma Cell Culture, min. $90 \%$, St. Louis, USA); BA $(2.22,4.48$, and $8.97 \mu \mathrm{M})$, N6-(2-isopentenyl) adenine (2iP; 2.44, 4.83, and $9.65 \mu \mathrm{M}$ ); or thidiazuron (TDZ; 2.27, 4.55, and $9.1 \mu \mathrm{M}$ ), individually. MS medium without PGRs served as a control. The $\mathrm{pH}$ of the medium was adjusted, autoclaved, and cultures were incubated as mentioned in the shoot induction stage. The number and length $(\mathrm{cm})$ of axillary shoots/explant were recorded after 3 weeks of culture. Subculturing was done every 3 weeks. 


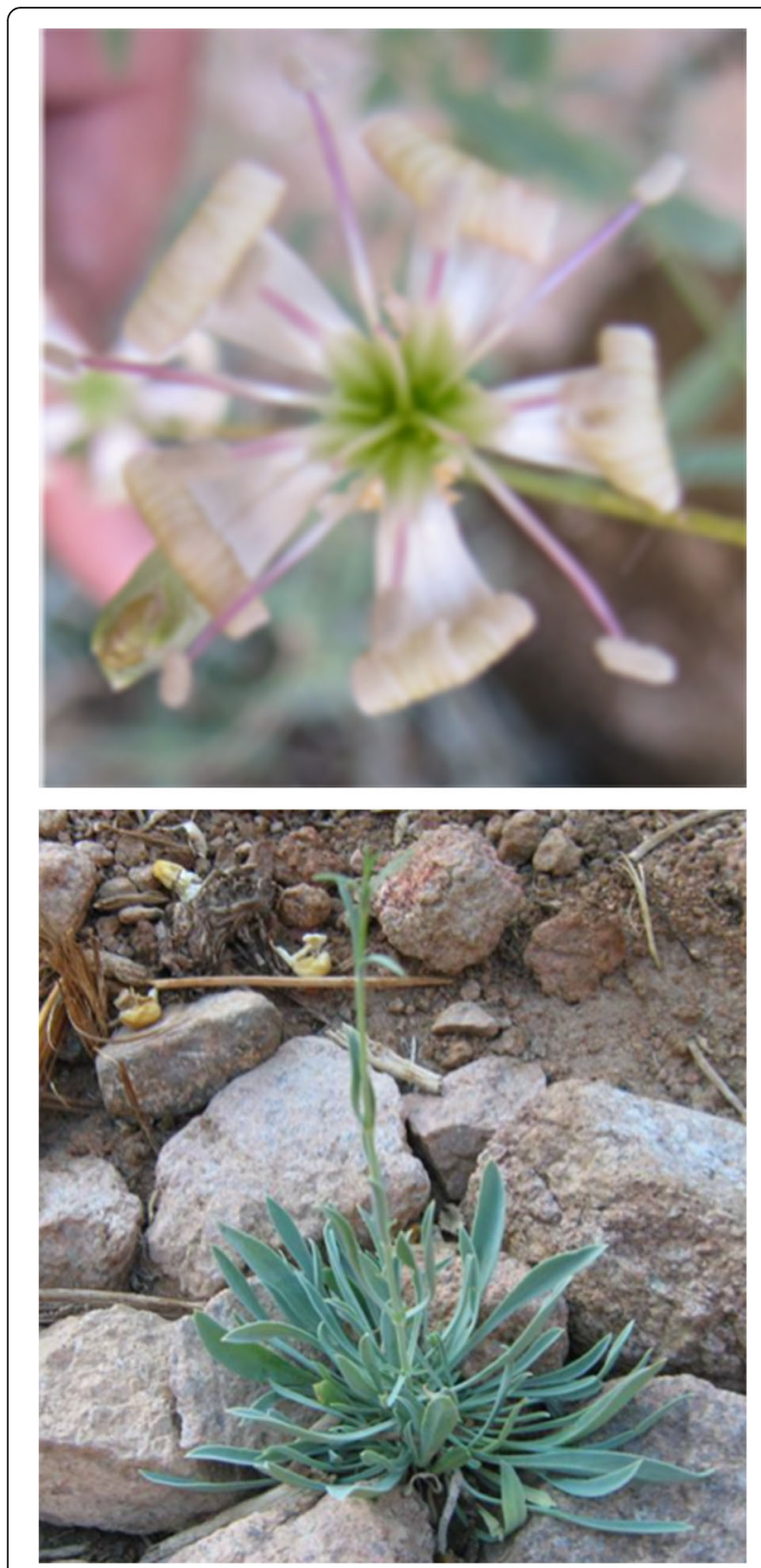

Fig. 2 Silene schimperiana plant growing naturally in Gebel Tennia, Saint Katherine, Southern Sinai, with a close up view of a flower

Rooting and acclimatization stages The multiplied axillary shoot clusters were transferred for rooting on quarter-strength MS medium supplemented with different combinations of indole-3-butyric acid (IBA; Sigma Cell Culture, min. 90\%, St. Louis, USA) at 4.92 and $9.85 \mu \mathrm{M}$ and NAA at 5.38 and $10.75 \mu \mathrm{M}$. Quarterstrength MS medium without PGRs served as a control for rooting induction. The $\mathrm{pH}$ was adjusted, media autoclaved, and cultures were incubated as mentioned in the previous stages. The percentage of rooted shoots (rooting \%) and the number and length $(\mathrm{cm})$ of roots/explant were scored after 4 weeks of culture on the rooting medium.

The rooted plantlets were removed from the nutrient medium and washed thoroughly with distilled water to eliminate the residues of the medium, then were transferred to plastic pots in a mixture of sand and peat (1: 2 $\mathrm{v} / \mathrm{v}$ ) (Peat moos, PROMIX ${ }^{\oplus}$ ). The pots were covered by translucent polythene plastic bags to maintain high humidity and prevent the dissection of the newly transferred plantlets. Transplants were irrigated and the plastic bags were pored (one pore/ 5 days for 5 weeks) to decrease the humidity and acclimatize the plants to the external atmosphere gradually. After 6 weeks, the plastic bags were removed completely and the plants allowed to grow under open conditions.

\section{Experimental design and statistical analysis}

In vitro experiments were subjected to the completely randomized design. At least ten replicates were cultured for each treatment and the experiments were repeated twice. One-way analysis of variance (ANOVA) was used to evaluate significant differences between the mean values of different treatments, using Duncan's Multiple Range Test [22] as modified by Snedecor and Cochrane [23]. The differences between means were compared at $p<0.05$.

\section{DNA barcode analysis \\ Extraction and purification of DNA}

Silene schimperiana leaf specimens were collected and ground to a fine powder in liquid nitrogen using a sterile mortar and pestle. For DNA extraction and purification, DNeasy Plant Kit (Qiagen, Germany) was used. The concentration and quality of extracted DNA were estimated by running on $1 \%$ agarose gel electrophoresis, using a DNA size marker (Lambda DNA Hind III digest Phi X 174/HaeIII digest).

\section{$P C R$ and gene sequencing}

The PCR reaction was carried out as reported by Ibrahim et al. [24] in a total volume of $50 \mu \mathrm{L}$ PCR master mixture consisted of the following: 1x buffer (Promega, USA), $15 \mathrm{mM} \mathrm{MgCl}_{2}, 0.2 \mathrm{mM}$ dNTPs (Promega, USA), 20 pcoml of each primer (Invitrogen, USA), $1 \mathrm{u}$ of Taq DNA polymerase (GoTaq, Promega, USA), 40 ng DNA and ultra-pure water to the final volume. DNA barcoding was performed with the ncDNA ITS gene and two cpDNA genes, rpoC1 and $r b c L$. For PCR amplification and sequencing of $r p o C 1, r b c L$, and ITS, the following primer pairs were used: ITS-F $\left(5^{\prime}-\mathrm{CCT}\right.$ TAT CAT TTA GAG GAA GGA G-3'), ITS-R (5' -TCC TCC GCT TAT TGA TAT GC-3'); rpoC1-F (5'-GGC AAA GAG GGA AGA TTT CG-3'), rpoC1-R (5'-CCA TAA GCA TAT CTT GAG TTG G-3'); and rbcL-F (5' - ATG TCA CCA 
CAA ACA GAA AC-3'), $r b c L-R$ (5'-TCG CAT GTA CCT GCA GTA GC-3'). The average amplicon sizes/bp were 722,520 , and 693 for ITS, rpoC1, and rbcL, respectively.

The PCR was carried out with a Perkin-Elmer/GeneAmp ${ }^{\circ}$ PCR System 9700 (PE Applied Biosystems, USA) programmed to fulfill 40 cycles after an initial denaturation cycle for $5 \mathrm{~min}$ at $94{ }^{\circ} \mathrm{C}$. Each cycle consisted of a denaturation step at $94{ }^{\circ} \mathrm{C}$ for $30 \mathrm{~s}$, an annealing step at $50{ }^{\circ} \mathrm{C}$ for $30 \mathrm{~s}$, and an elongation step at $72^{\circ} \mathrm{C}$ for $30 \mathrm{~s}$. The primer extension segment was extended to $7 \mathrm{~min}$ at $72^{\circ} \mathrm{C}$ in the final cycle.

The amplification products were determined by electrophoresis in a $1.5 \%$ agarose gel using ethidium bromide $(0.5 \mathrm{ug} / \mathrm{ml})$ in $1 \mathrm{X}$ Tris borate Edita (TBE) buffer at 95 volts. For PCR product size determination, a $100 \mathrm{bp}$ DNA ladder (Promega, USA) was used as a molecular size standard. Gel images were visualized using a UV transilluminator and photographed using a Gel Documentation System (BIO-RAD 2000, USA).

Purification of PCR products was carried out by a QIAquick PCR Purification Kit (Qiagen, USA). The PCR product was sequenced using the dideoxynucleotide chain termination method with a DNA sequencer (ABI 3730XL, Applied Biosystems) (Microgen, Korea) and a BigDye Terminator version 3.1 Cycle Sequencing RR-100 Kit (Applied Biosystems, USA) according to the protocol supplied by the manufacturer.

\section{Assignment of species}

DNA barcoding of Silene schimperiana was carried out using the Basic Local Alignment Tool (BLAST) available on the National Center of Biotechnology Information (NCBI) website. All sequences were submitted to GenBank, USA. It provided MK628682, MK628685, and MK628687 accession numbers for the nucleotide sequences.
BLAST searches were applied to all produced sequences using the online databases (DDBJ/EMBL/GenBank), analyzed using BLASTN 2.9.0 program (http:// www.ncbi.nlm.nih.gov/BLAST), and aligned using Align Sequences Nucleotide BLAST. The identification of species was considered successful when the highest similarity percentage included a single species scored more than 97\% [20]. Phylogenetic analysis was conducted using MAFFTv6.864, http://www.genome.jp/tools-bin/ mafft, and phylogenetic trees were generated.

\section{Results \\ In vitro propagation of Silene schimperiana Establishment of in vitro culture}

Eighty percent of Silene schimperiana seeds was survived and germinated when sterilized with $1 \%$ of sodium hypochlorite solution for $15 \mathrm{~min}$ and planted on 1/2 MS medium supplemented with $5.77 \mu \mathrm{M} \mathrm{GA}_{3}$. Shoot tips and stem nodal segments were excised from 1-monthold seedlings and transferred to the different establishment media to achieve optimization of the in vitro culture (Table 1). MS medium supplemented with $2.89 \mu \mathrm{M}$ $\mathrm{GA}_{3}, 1.08 \mu \mathrm{M} \mathrm{NAA}$, and different concentrations of either BA or Kin was examined. All treatments gave $100 \%$ of both survived explants and growth formation for both shoot tip and stem nodal segment explants.

Concerning shoot tip explant, the mean number and length of axillary shoots per explant ranged between 2.0 and 3.7 shoots with a length of 1.3 and $2.91 \mathrm{~cm}$, respectively. The maximum number and length of axillary shoots were achieved on the medium supplemented with $1.16 \mu \mathrm{M}$ Kin (Fig. 3a). Increasing the concentration of Kin led to a decrease in the number and length of axillary shoots. The same trend was observed with BA, as the highest mean number and length of axillary shoots per explant was recorded at the lowest concentration $(1.11 \mu \mathrm{M})$ and it decreased by increasing BA concentration (Table 1).

Table 1 Effect of Murashige and Skoog (MS) medium supplemented with $2.89 \mu \mathrm{M}$ gibberellic acid (GA3) and $1.08 \mu \mathrm{M}$ anaphthaleneacetic acid (NAA) in addition to 6-benzyl adenine (BA) or kinetin (Kin) on the in vitro establishment of Silene schimperiana shoot tip and stem nodal segment explants. All treatments gave 100\% of both survived explants and growth formation

\begin{tabular}{|c|c|c|c|c|c|}
\hline \multicolumn{2}{|c|}{ Cytokinin conc. $(\mu \mathrm{M})$} & \multicolumn{2}{|l|}{ Shoot tip } & \multicolumn{2}{|l|}{ Stem nodal segment } \\
\hline BA & Kin & $\begin{array}{l}\text { Mean no. of axillary } \\
\text { shoots/explant }\end{array}$ & $\begin{array}{l}\text { Mean length of } \\
\text { axillary shoots }(\mathrm{cm})\end{array}$ & $\begin{array}{l}\text { Mean no. of axillary } \\
\text { shoots/explant }\end{array}$ & $\begin{array}{l}\text { Mean length of axillary } \\
\text { shoots }(\mathrm{cm})\end{array}$ \\
\hline 0.00 & 0.00 & $2.0^{b}$ & $1.30^{\mathrm{b}}$ & $2.3^{b}$ & $1.39^{b}$ \\
\hline 1.11 & 0.00 & $2.7^{\mathrm{ab}}$ & $2.00^{\mathrm{ab}}$ & $2.9^{b}$ & $2.28^{\mathrm{ab}}$ \\
\hline 2.22 & 0.00 & $2.6^{\mathrm{ab}}$ & $1.70^{\mathrm{b}}$ & $2.9^{b}$ & $2.06^{\mathrm{ab}}$ \\
\hline 4.48 & 0.00 & $2.0^{b}$ & $1.43^{b}$ & $2.3^{b}$ & $1.50^{\mathrm{b}}$ \\
\hline 0.00 & 1.16 & $3.7^{\mathrm{a}}$ & $2.91^{\mathrm{a}}$ & $4.3^{\mathrm{a}}$ & $3.00^{\mathrm{a}}$ \\
\hline 0.00 & 2.33 & $3.2^{\mathrm{ab}}$ & $2.10^{a b}$ & $4.0^{\mathrm{a}}$ & $2.33^{\mathrm{ab}}$ \\
\hline 0.00 & 4.65 & $2.2^{b}$ & $1.70^{\mathrm{b}}$ & $2.4^{\mathrm{b}}$ & $2.10^{a b}$ \\
\hline
\end{tabular}



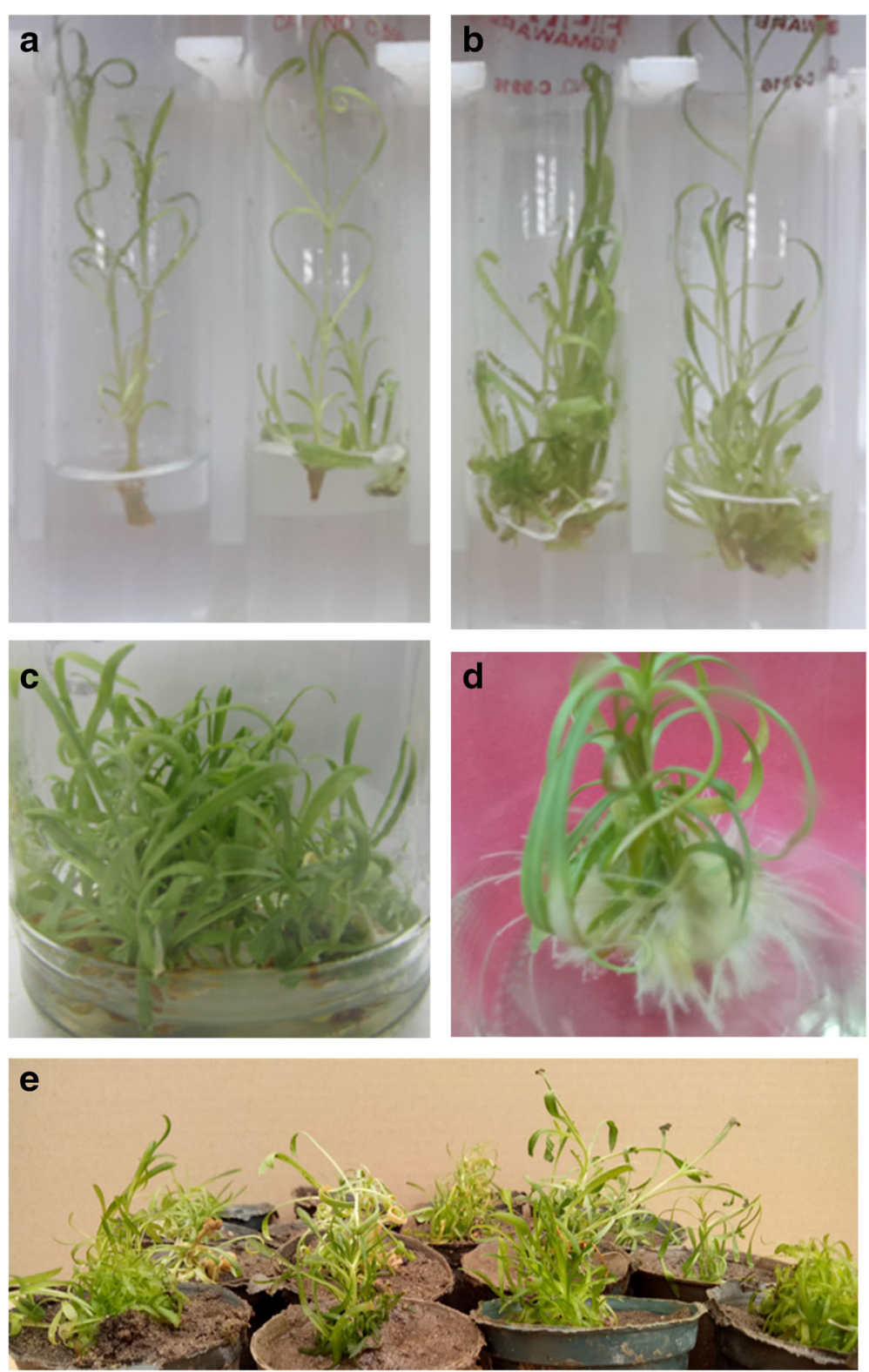

Fig. 3 In vitro propagation of Silene schimperiana; (a) in vitro establishment of shoot tip, (b) in vitro establishment of stem nodal segment, (c) multiplication of axillary shoots, (d) rooted plantlet, and (e) acclimatization of transplants in the greenhouse

Concerning the stem nodal segment explant, as shown in Table 1, it recorded higher numbers and lengths of axillary shoots per explant on all tested media comparing to shoot tip explant. The mean number and length of axillary shoots per explant ranged between 2.3 and 4.3 shoots and 1.39 and $3.0 \mathrm{~cm}$, respectively. The highest number and length of axillary shoots were achieved on the same optimum medium for shoot tip explant that supplemented with $1.16 \mu \mathrm{M}$ Kin (Fig. 3b), and they also decreased with increasing the concentration of Kin. On the other hand, BA gave lower values of the mean number and length of axillary shoots compared to the same concentrations of Kin. Concerning the control treatment without cytokinin, it gave the minimum response for both explants.

In conclusion, for the in vitro establishment of Silene schimperiana, MS medium supplemented with $2.89 \mu \mathrm{M}$ $\mathrm{GA}_{3}, 1.08 \mu \mathrm{M} \mathrm{NAA}$, and $1.16 \mu \mathrm{M}$ Kin was the best medium for stem nodal segment and shoot tip explants. Comparing the two tested explants, it was found that the stem nodal segment had a higher shoot induction capacity than the shoot tip. 
Table 2 Effect of Murashige and Skoog (MS) medium supplemented with 6-benzyl adenine (BA), N6-(2-isopentenyl) adenine (2iP), or thidiazuron (TDZ) on the in vitro multiplication of Silene schimperiana axillary shoots

\begin{tabular}{|c|c|c|c|c|}
\hline \multicolumn{3}{|c|}{ Cytokinin conc. $(\mu \mathrm{M})$} & \multirow{2}{*}{$\begin{array}{l}\text { Mean no. of } \\
\text { axillary shoots/ } \\
\text { explant }\end{array}$} & \multirow{2}{*}{$\begin{array}{l}\text { Mean length } \\
\text { of axillary } \\
\text { shoots }(\mathrm{cm}) \\
\end{array}$} \\
\hline BA & $2 \mathrm{iP}$ & TDZ & & \\
\hline 0.00 & 0.00 & 0.00 & $3.27^{d}$ & $1.4^{\mathrm{a}}$ \\
\hline 2.22 & 0.00 & 0.00 & $5.45^{b c}$ & $1.3^{\mathrm{a}}$ \\
\hline 4.48 & 0.00 & 0.00 & $9.27^{\mathrm{a}}$ & $1.9^{\mathrm{a}}$ \\
\hline 8.97 & 0.00 & 0.00 & $7.27^{\mathrm{b}}$ & $1.8^{\mathrm{a}}$ \\
\hline 0.00 & 2.44 & 0.00 & $4.36^{\mathrm{cd}}$ & $2.1^{\mathrm{a}}$ \\
\hline 0.00 & 4.83 & 0.00 & $4.73^{c d}$ & $1.8^{\mathrm{a}}$ \\
\hline 0.00 & 9.65 & 0.00 & $5.64^{\mathrm{bc}}$ & $1.8^{\mathrm{a}}$ \\
\hline 0.00 & 0.00 & 2.27 & $4.00^{c d}$ & $1.5^{\mathrm{a}}$ \\
\hline 0.00 & 0.00 & 4.55 & $3.64^{\mathrm{cd}}$ & $1.9^{\mathrm{a}}$ \\
\hline 0.00 & 0.00 & 9.10 & $5.18^{\mathrm{cd}}$ & $1.4^{\mathrm{a}}$ \\
\hline
\end{tabular}

Means in the same column with different letters are statistically significantly different at $p \leq 0.05$

\section{Multiplication of axillary shoots}

Multiplication of the in vitro established axillary shoots was achieved as shown in Table 2 . All tested treatments enhanced multiple shoots production, which ranged between 3.27 and 9.27 axillary shoots per explant. The significantly highest mean number of axillary shoots per explant was recorded on MS medium supplemented with $4.48 \mu \mathrm{M}$ BA, followed by $8.97 \mu \mathrm{M}$ BA. Concerning the other tested cytokinins, $2 \mathrm{iP}$ ranked next as it produced a higher number of axillary shoots than the same concentrations of TDZ. The number of axillary shoots increased by increasing the concentration of $2 \mathrm{iP}$.

Regarding the mean length of axillary shoots, it was insignificantly different for all tested treatments and the maximum length of $2.1 \mathrm{~cm}$ was recorded with $2.44 \mu \mathrm{M}$ $2 \mathrm{iP}$. The medium without cytokinin recorded the lowest mean number and length of axillary shoots. In this experiment, 2iP (at 4.83 and $9.65 \mu \mathrm{M}$ ) and TDZ (at all tested concentrations) caused the vitrification of axillary shoots.
In conclusion, BA was the most effective tested cytokinin for the multiplication of non-vitreous axillary shoots, compared to both $2 \mathrm{iP}$ and TDZ. While TDZ gave the minimum response. The significantly highest mean number of axillary shoots per explant was recorded on MS medium supplemented with $4.48 \mu \mathrm{M}$ BA (Fig. 3c).

\section{Rooting of axillary shoots and acclimatization of plantlets}

Combinations between IBA and NAA were tested for rooting of axillary shoots of Silene schimperiana and gave promising results as presented in Table 3.

The rooting percentage reached $100 \%$ using $4.92 \mu \mathrm{M}$ IBA in combination with either 5.38 or $10.75 \mu \mathrm{M}$ NAA in quarter-strength MS medium. Also, the mean number and length of roots per explant and mean length of axillary shoots were maximum at the same concentrations. The medium without auxin recorded the lowest rooting percentage, mean number and length of roots, and mean length of axillary shoots. Regarding the highest number of roots, the concentration of $4.92 \mu \mathrm{M}$ IBA in combination with $10.75 \mu \mathrm{M}$ NAA is the optimum concentration for the rooting of Silene schimperiana, which produced 34.5 roots per explant with also the highest mean length of roots $(7.4 \mathrm{~cm})$ and axillary shoots $(8.5 \mathrm{~cm})$ (Fig. 3d), followed by the same concentration of IBA in combination with $5.38 \mu \mathrm{M}$ NAA (30.13 roots per explant of 6.0 $\mathrm{cm}$ roots and $7.0 \mathrm{~cm}$ axillary shoots).

At the end of the rooting stage, the rooted plantlets were successfully acclimatized to ex vitro conditions into pots containing a soil-peat mixture $(1: 2 \mathrm{v} / \mathrm{v})$ and grown in greenhouse conditions with an approximately $75 \%$ survival rate (Fig. 3e).

\section{Identification of Silene schimperiana by DNA barcode analysis}

For the identification and classification of the rare endemic Silene schimperiana plant for conservation, DNA barcoding was carried out. The results of BLAST matching and phylogenic tree analysis of Silene schimperiana are shown in Tables 4, 5, and 6 and Figs. 4, 5, 6, and 7. The plant species of the highest percentages of similarity

Table 3 Effect of quarter-strength Murashige and Skoog (1/4 MS) medium supplemented with indole-3-butyric acid (IBA) and anaphthaleneacetic acid (NAA) at different combinations on the rooting of Silene schimperiana multiple shoot clusters

\begin{tabular}{|c|c|c|c|c|c|}
\hline \multicolumn{2}{|c|}{ Auxin conc. $(\mu \mathrm{M})$} & \multirow{2}{*}{$\begin{array}{l}\text { Rooting } \\
(\%)\end{array}$} & \multirow{2}{*}{$\begin{array}{l}\text { Mean no. } \\
\text { of roots/ } \\
\text { explant }\end{array}$} & \multirow{2}{*}{$\begin{array}{l}\text { Mean } \\
\text { length of } \\
\text { roots }(\mathrm{cm})\end{array}$} & \multirow{2}{*}{$\begin{array}{l}\text { Mean length } \\
\text { of axillary } \\
\text { shoots }(\mathrm{cm})\end{array}$} \\
\hline IBA conc. $(\mu \mathrm{M})$ & NAA conc. $(\mu \mathrm{M})$ & & & & \\
\hline 0.00 & 0.00 & 33 & $16.88^{c}$ & $3.4^{e}$ & $5.0^{c}$ \\
\hline 4.92 & 5.38 & 100 & $30.13^{\mathrm{a}}$ & $6.0^{\mathrm{b}}$ & $7.0^{\mathrm{b}}$ \\
\hline 4.92 & 10.75 & 100 & $34.50^{\mathrm{a}}$ & $7.4^{\mathrm{a}}$ & $8.5^{\mathrm{a}}$ \\
\hline 9.85 & 5.38 & 66 & $22.31^{b}$ & $5.2^{c}$ & $6.5^{\mathrm{b}}$ \\
\hline 9.85 & 10.75 & 66 & $18.65^{b c}$ & $4.2^{d}$ & $5.5^{c}$ \\
\hline
\end{tabular}

Means in the same column with different letters are statistically significantly different at $p \leq 0.05$ 
Table 4 DNA barcode of internal transcribed spacer (ITS) downloaded from GenBank database including plant species with similarity percentage of more than $97.78 \%$

\begin{tabular}{lllll}
\hline Plant species & Accession no. & $\boldsymbol{E}$ value & Query coverage (\%) & Similarity (\%) \\
\hline Silene caesarea & MK530524.1 & 0.0 & 66 & 96.38 \\
Silene danaensis & KX757625.1 & 0.0 & 66 & 99.17 \\
Silene armena & KX757619.1 & 0.0 & 66 & 98.76 \\
Silene dianthoides & KX757626.1 & 0.0 & 66 & 98.14 \\
Silene lychnidea & KX852609.1 & 0.0 & 63 & 97.80 \\
Silene marschallii & KX757622.1 & 0.0 & 66 & 97.93 \\
Silene shanbashakensis & KX757623.1 & 0.0 & 64 & 97.85 \\
Silene bupleuroides & MK554643.1 & 0.0 & 66 & 97.93 \\
Silene idaea & KX75618.1 & 0.0 & 62 & 97.79 \\
Silene lycaonica & KX757621.1 & 0.0 & 66 & 98.54 \\
Silene longipetala & KX757616.1 & 0.0 & 66 & 98.14 \\
Silene baldshuanica & KX757615.1 & 0.0 & 63 & 98.48 \\
\hline
\end{tabular}

are represented. Newly generated sequences of the three markers: ITS, $r p o C 1$, and $r b c L$ were used as barcodes. The alignments of ITS, $r p o C 1$, and $r b c L$ sequences against GenBank accessions yielded a query coverage between 62 to $66 \%, 83$ to $94 \%$, and 74 to $80 \%$, respectively (Tables 4 , 5 , and 6). Sequencing for ITS, $r p o C 1$, and $r b c L$ regions of Silene schimperiana resulted in 697, 495 and 668 bp sequences (affected length of the query), respectively. Sequence alignment analysis revealed 100\% the genus Silene hits of 737-874, 651-880, and 922-972 bp length for ITS, $r p o C 1$, and $r b c L$ sequences, respectively.

The highest similarity percentages between Silene schimperiana and the other recorded Silene species reached $99.38 \%$ for ITS with Silene caesarea, 99.33\% for rpoC1 with Silene vulgaris and $99.03 \%$ for $r b c L$ with Silene virginica (Tables 4, 5, and 6). The $r b c L$ sequence showed $98.21 \%$ similarity with the same species, Silene schimperiana. So, Silene schimperiana was successfully identified on both species and genus levels for the $r b c L$ marker and the genus level for ITS and rpoC1 markers.

The phylogenetic trees of the plant species with the highest similarity percentages have a fan shape (Figs. 4, 5,6 , and 7), showing clustering of closely related species together and scattering of relatively distantly related species. The combined phylogenetic analysis represented in Fig. 7 shows that the three tested markers support the inclusion of Silene schimperiana in the genus Silene and the most closely related species are Silene caesarea, Silene schimperiana, and Silene akinfievii.

\section{Discussion}

In vitro propagation of Silene schimperiana

Shoot tips and stem nodal segments were successfully established in vitro on MS medium supplemented with $2.89 \mu \mathrm{M} \mathrm{GA}, 1.08 \mu \mathrm{M}$ NAA and different concentrations of either BA or Kin. The main property of $\mathrm{GA}_{3}$ is

Table 5 DNA barcode of RNA polymerase subunit (rpoC1) downloaded from GenBank database including plant species with similarity percentage of more than $98.77 \%$

\begin{tabular}{lllll}
\hline Plant species & Accession no. & E value & Query coverage (\%) & Similarity (\%) \\
\hline Silene akinfievii & FN821234.1 & 0.0 & 90 & 99.15 \\
Silene schwarzenbergii & FN821266.1 & 0.0 & 90 & 99.15 \\
Silene vulgaris & HE687421.1 & 0.0 & 86 & 99.33 \\
Silene latifolia & FN821258.1 & 0.0 & 83 & 99.31 \\
Silene diclinis & FN821236.1 & 0.0 & 83 & 99.31 \\
Silene marizii & FN821262.1 & 0.0 & 90 & 98.93 \\
Silene quadriloba & FN821265.1 & 0.0 & 90 & 98.93 \\
Silene pygmaea & FN821264.1 & 0.0 & 90 & 98.93 \\
Silene mentagensis & HE687385.1 & 0.0 & 86 & 98.89 \\
Silene paradoxa & KF527887.1 & 0.0 & 94 & 98.98 \\
Silene uniflora & KY562597.1 & 0.0 & 94 & 98.78 \\
\hline
\end{tabular}


Table 6 DNA barcode of 1,5-bisphosphate carboxylase/oxygenase large subunit ( $r b c L$ ) downloaded from GenBank database including plant species with similarity percentage of more than $98.2 \%$

\begin{tabular}{|c|c|c|c|c|}
\hline Plant species & Accession no. & $E$ value & Query coverage (\%) & Similarity (\%) \\
\hline Silene schimperiana & MF66859.1 & 0.0 & 80 & 98.21 \\
\hline Silene schafta & EF418563.1 & 0.0 & 77 & 98.89 \\
\hline Silene repens & MG247524.1 & 0.0 & 77 & 98.50 \\
\hline Silene pygmaea & EF418557.1 & 0.0 & 77 & 98.70 \\
\hline Silene leucophylla & MK055336.1 & 0.0 & 77 & 98.88 \\
\hline Silene sibirica & MG246549.1 & 0.0 & 77 & 98.31 \\
\hline Silene acaulis & KC484097.1 & 0.0 & 77 & 98.31 \\
\hline Silene nutans subsp. nutans & HE963670.1 & 0.0 & 77 & 98.69 \\
\hline Silene antirrhina & KJ773896.1 & 0.0 & 75 & 98.67 \\
\hline Silene laciniata & EF418562.1 & 0.0 & 77 & 98.52 \\
\hline Silene virginica & KX397963.1 & 0.0 & 74 & 99.03 \\
\hline Silene involucrata & JN965995.1 & 0.0 & 74 & 98.84 \\
\hline Silene delavayi & EF418558.1 & 0.0 & 77 & 98.33 \\
\hline Silene vulgaris subsp. vulgaris & HE963671.1 & 0.0 & 77 & 98.32 \\
\hline Silene latifolia subsp. alba & HE963667.1 & 0.0 & 77 & 98.32 \\
\hline Silene vulgaris & KF602215.1 & 0.0 & 76 & 98.48 \\
\hline
\end{tabular}

the stimulation of cell division and elongation and the presence of auxin (NAA) in the medium enhances the action of $\mathrm{GA}_{3}[8,25]$. This was confirmed by Kritskaya et al. [8], who successfully micropropagated Silene cretacea by using $\mathrm{GA}_{3}$ and auxin in the medium in a combination with cytokinin.

Don Palmer and Keller [26] reported that explant source is one of the important factors for the successful establishment of in vitro culture. According to the results of the present study, when the two explant types were compared, it was found that the stem nodal segment had a higher shoot induction capacity than the shoot tip. Similarly, Çördük et al. [9] found that nodal explant was the most effective explant for shoot regeneration of Silene bolanthoides.

For the in vitro establishment of Silene schimperiana, MS medium supplemented with $2.89 \mu \mathrm{M} \mathrm{GA}_{3}, 1.08 \mu \mathrm{M}$ $\mathrm{NAA}$, and $1.16 \mu \mathrm{M}$ Kin was the best medium for stem nodal segment and shoot tip explants, respectively. Kinetin, together with the auxin (NAA), participates in the organogenesis process in plants. This is supported by

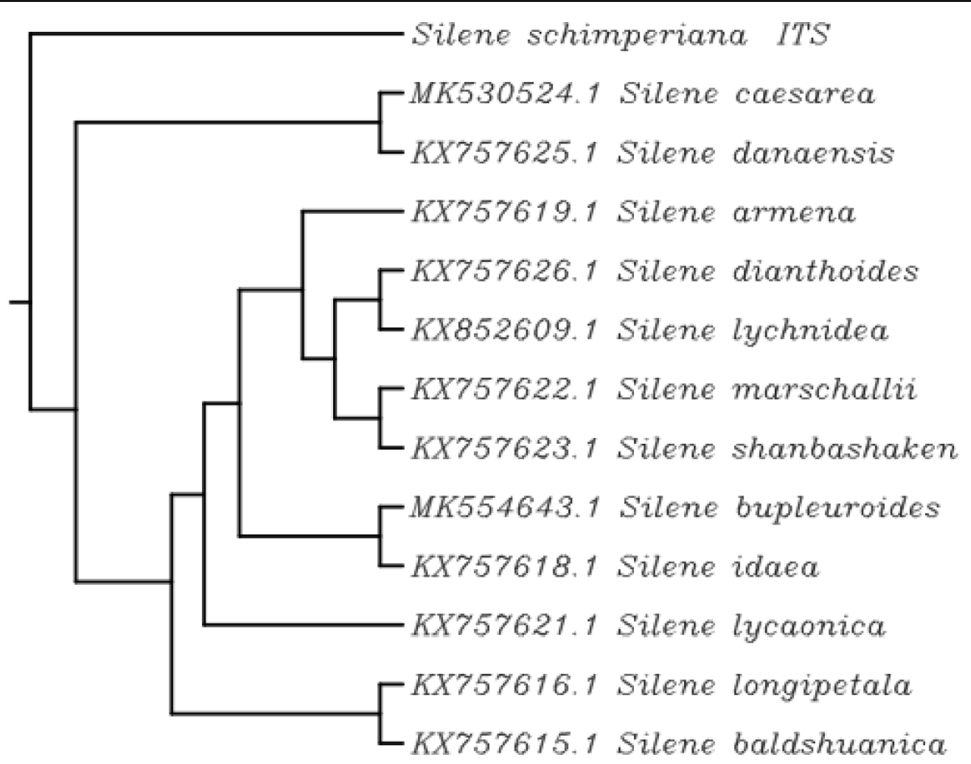

Fig. 4 Phylogenetic tree of Silene schimperiana using the ncDNA: internal transcribed spacer (ITS) 


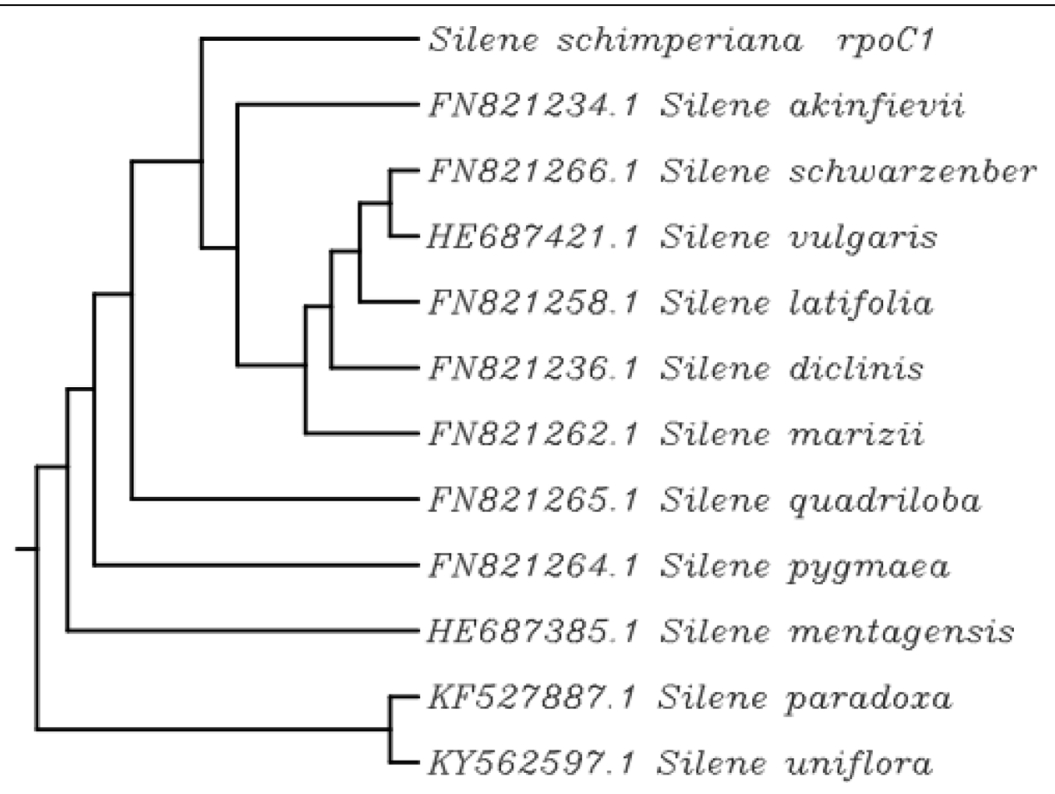

Fig. 5 Phylogenetic tree of Silene schimperiana using the cpDNA marker: RNA polymerase subunit (rpoCl)

Kritskaya et al. [8], who found that Kin was effective in the micropropagation of Silene cretacea. Also, it has been reported on other Silene species that cytokinin and auxin are required in combination in tissue culture media and are the best for the initial shoot induction phase [10].

Multiplication of axillary shoots was influenced by cytokinin type and concentration. The significantly highest mean number of axillary shoots was recorded with BA, and 2iP ranked next, followed by TDZ. In this experiment, $2 \mathrm{iP}$ and TDZ caused the vitrification of axillary shoots. Therefore, it is important to select a proper concentration of cytokinin, because high concentrations cause vitrification and somaclonal variations [27]. Cytokinins (BA, 2iP, and TDZ) had multifunction in the physiological processes and the development of the plant

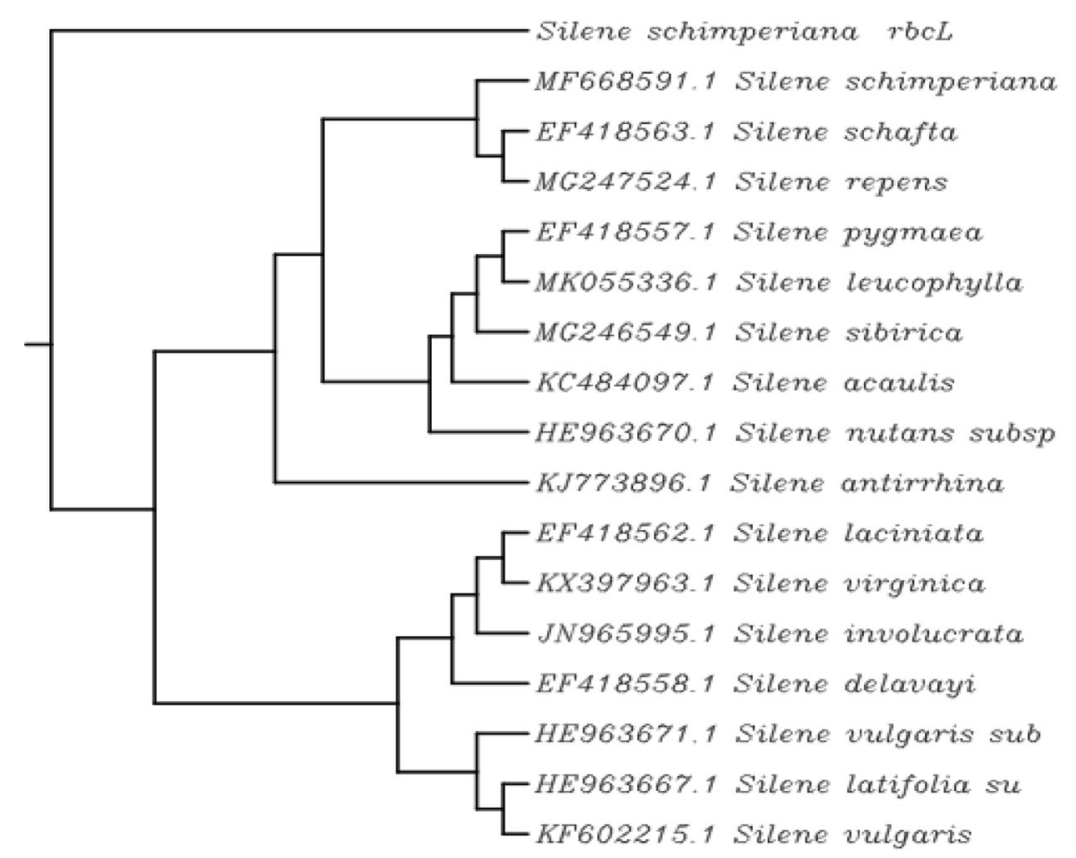

Fig. 6 Phylogenetic tree of Silene schimperiana using the cpDNA marker: 1,5-bisphosphate carboxylase/oxygenase large subunit ( $r b c L$ ) 


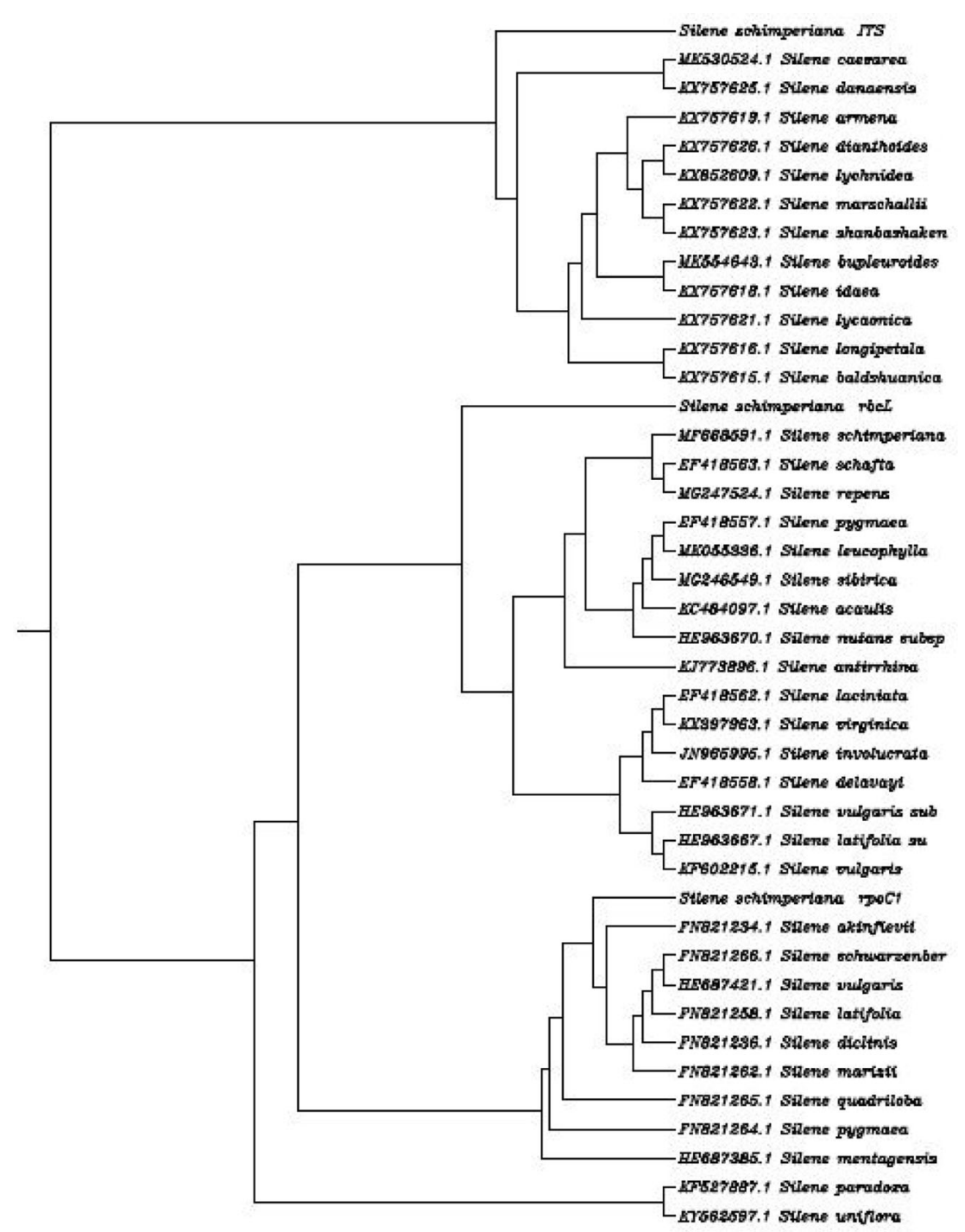

Fig. 7 Combined phylogenetic tree of Silene schimperiana using the three markers: internal transcribed spacer (ITS), RNA polymerase subunit (rpoC1), and 1,5-bisphosphate carboxylase/oxygenase large subunit ( $r b c L)$

as cell division and enlargement and stimulation of protein synthesis and enzyme activity [28]. The most typical cytokinin function in the plant in vitro culture is the suppression of apical dominance and the stimulation of lateral buds, due to the differentiation of vascular tissue between the axillary buds and vascular bundles of the main stem $[8,29]$.

The optimum medium for multiplication of axillary shoots was MS medium supplemented with $4.48 \mu \mathrm{M}$ BA. It is clear from the results that the proper choice of cytokinin is one of the most important factors affecting the multiplication of axillary shoots. In the present study, BA was more effective in the production of non-vitreous multiple axillary shoots than $2 \mathrm{iP}$ and TDZ. The high efficiency of BA could be contributed to that it considered the most stable among the tested cytokinins, because of the stability of the aromatic side-chain substituted at N6 that is higher than the isoprenoid chain of 2iP. Also, some of the conjugated forms of BA are produced during BA metabolism, extending its action [30, 31]. Furthermore, BA is not a suitable substrate of cytokinin oxidase enzyme, which is responsible for the endogenous cytokinin balance [31]. Moreover, it is worth mentioning that among the various cytokinins, BA is the most effective, preferable, and cheapest cytokinin used for in vitro shoot multiplication [10]. Regarding TDZ, its minimum effect in comparison with $\mathrm{BA}$ and $2 \mathrm{iP}$ may be contributed to that in some systems, the synergistic effect of TDZ with other cytokinin or auxin was found more effective 
than using it individually [32]. The highest shoot multiplication ability of BA has also been reported for other Silene species; where MS medium supplemented with $4.48 \mu \mathrm{M} \mathrm{BA}$ was optimum for the multiplication of non-vitreous shoots of Silene fabaria with sufficient length [10]. Additionally, BA has been the most widely used cytokinin for improving the number and length of shoots in various Silene species; such as for regenerated shoots from callus of Silene vulgaris [32, 33] and axillary shoots from direct organogenesis in Silene bolanthoides [9].

Auxins are important PGRs for in vitro culture systems for root formation [10]. The natural IBA and the synthetic NAA auxins were chosen for rooting, because of their low oxidative rate and high stability in the plant in vitro culture. In particular, IBA is more stable than NAA; therefore, it is the most widely used auxin for root induction [10, 34]. The optimum medium for rooting of axillary shoots of Silene schimperiana was quarter-strength MS medium supplemented with $4.92 \mu \mathrm{M}$ IBA in combination with $10.75 \mu \mathrm{M}$ NAA. It gave $100 \%$ rooting with the highest mean number and length of roots per explant and mean length of axillary shoots. The number of roots is considered an important factor for enhancing the survival of plants during acclimatization and is a sign of a qualitative rooting response [35]. Concerning other Silene species, the present study gave rooting response on completely different PGRs combinations. For example; for Silene leucophylla, MS medium supplemented with $4 \mathrm{mg} / \mathrm{L} \quad(17.94 \mu \mathrm{M}) \quad \mathrm{BA}, \quad 0.4 \mathrm{mg} / \mathrm{L}$ $(2.16 \mu \mathrm{M}) \mathrm{NAA}, 0.2 \mathrm{mg} / \mathrm{L}(0.58 \mu \mathrm{M}) \mathrm{GA}_{3}, 20 \%$ adenine sulfate, $0.05 \%$ silver nitrate, and $0.05 \%$ casein favored rooting of the proliferated shoots [6]. The optimal medium for rooting of Silene fetissovii, Silene obovata, Silene sussamyrica, and Silene ladyginae was MS medium supplemented with the addition of $1 \mathrm{mg} / \mathrm{L}(5.72 \mu \mathrm{M})$ indole acetic acid (IAA) [7]. In Silene fabaria subsp. domokina, 100\% rooting was obtained by incorporating $0.1 \mathrm{mg} / \mathrm{L}$ $(0.49 \mu \mathrm{M})$ IBA into the MS medium, followed by Kin and auxins combination [10]. On the other hand, in Silene bolanthoides, regenerated shoots were rooted on PGRs-free MS medium [9].

In the present study, a preliminary rooting experiment was carried out using each auxin individually and some of the treatments used with other Silene species from the literature (such as Saker et al. [6]. This experiment resulted in the production of weak unfunctional roots with a low percentage of rooting. This confirms that each plant species within a certain genus has its specific requirements and response to the propagation in vitro, which differs from the other species. Dolcet-Sanjuan et al. [34] confirm that the rooting response depends on different factors, such as type and concentration of auxin, species, and even the clone of a specific species. The plantlets with functional roots were successfully acclimatized in the greenhouse.

\section{Identification of Silene schimperiana by DNA barcode analysis}

To identify and classify plant species for conservation, traditional taxonomic tools are inadequate. Recently, the alternative approach of DNA barcoding is successfully introduced for authentication of rare and endemic plant species as an important base for evolutionary and ecological studies as well as for determining conservation priorities $[11,13]$. DNA barcoding provides proper identification of endemic plant species, which is very important to help in the conservation of natural plant genetic resources [20]. It is a reliable tool to identify a plant species and a short genetic sequence from a standard part of the genome that can be sufficient.

BLAST matching and phylogenic tree analysis of Silene schimperiana using the three markers: ITS, rpo $C 1$, and $r b c L$ as barcodes revealed $100 \%$ the genus Silene. It was reported earlier that on the species level, the identification of species is considered successful when the similarity percentage scores more than $95 \%$ and includes a single species. However, on the generic level, DNA barcoding is considered successful when all BLAST searches score similarity percentage of more than $95 \%$ and include a single genus [20]. In the present study, the highest similarity percentages between Silene schimperiana and the other recorded Silene species ranged between 99.03 and 99.38. The $r b c L$ sequence showed $98.21 \%$ similarity with the same species; Silene schimperiana (unpublished data). Therefore, according to the obtained data, the identification of Silene schimperiana was successful on both species and genus levels for the $r b c L$ marker and the genus level for ITS and rpoC1 markers.

The phylogenetic trees of Silene schimperiana using the three markers: ITS, rpoC1, and $r b c L$ and combined phylogenetic analysis supported the inclusion of Silene schimperiana in the genus Silene and the most closely related species are Silene caesarea, Silene schimperiana, and Silene akinfievii.

Phylogenetic analyses with a combination of nrDNA and cpDNA are one of the most effective methods to understand evolutionary relationships between and within species [36]. The results of the present study show a successful identification of Silene schimperiana on the species and genus levels. The success of species 
identification using DNA barcoding is contributing to the availability of nucleotide data of the corresponding taxa in the DNA sequences database [37]. However, additional experiments with other markers to entirely identify the plant more accurately are required. The present study reflects the potential use of DNA barcode analysis in documenting endemic endangered species concerning assigning to the proper taxonomic position.

\section{Conclusion}

Biotechnology tools including in vitro propagation and DNA barcoding should be applied to rare and endemic plant species against the loss of wild plant populations and for germplasm conservation. Ex situ conservation by in vitro propagation provides a high yield for commercial utilization of valuable plant species, can be used for improving genetic characteristics and producing clonal plants [10]. DNA barcoding should be applied parallel to the morphological classification of plants for the identification of species and genetic relationships for appropriate conservation of plants [33].

In conclusion, to the best of our knowledge, this is the first report on an efficient in vitro propagation protocol from shoot tip and stem nodal segment explants of Silene schimperiana with a satisfactory frequency of plant multiplication and production. Also, the molecular identification of Silene schimperiana was done using DNA barcode analysis for the proper conservation of the plant and to protect our intellectual property rights. A schematic diagram of the ex situ conservation program done in the present study for Silene schimperiana is presented in Fig. 8.

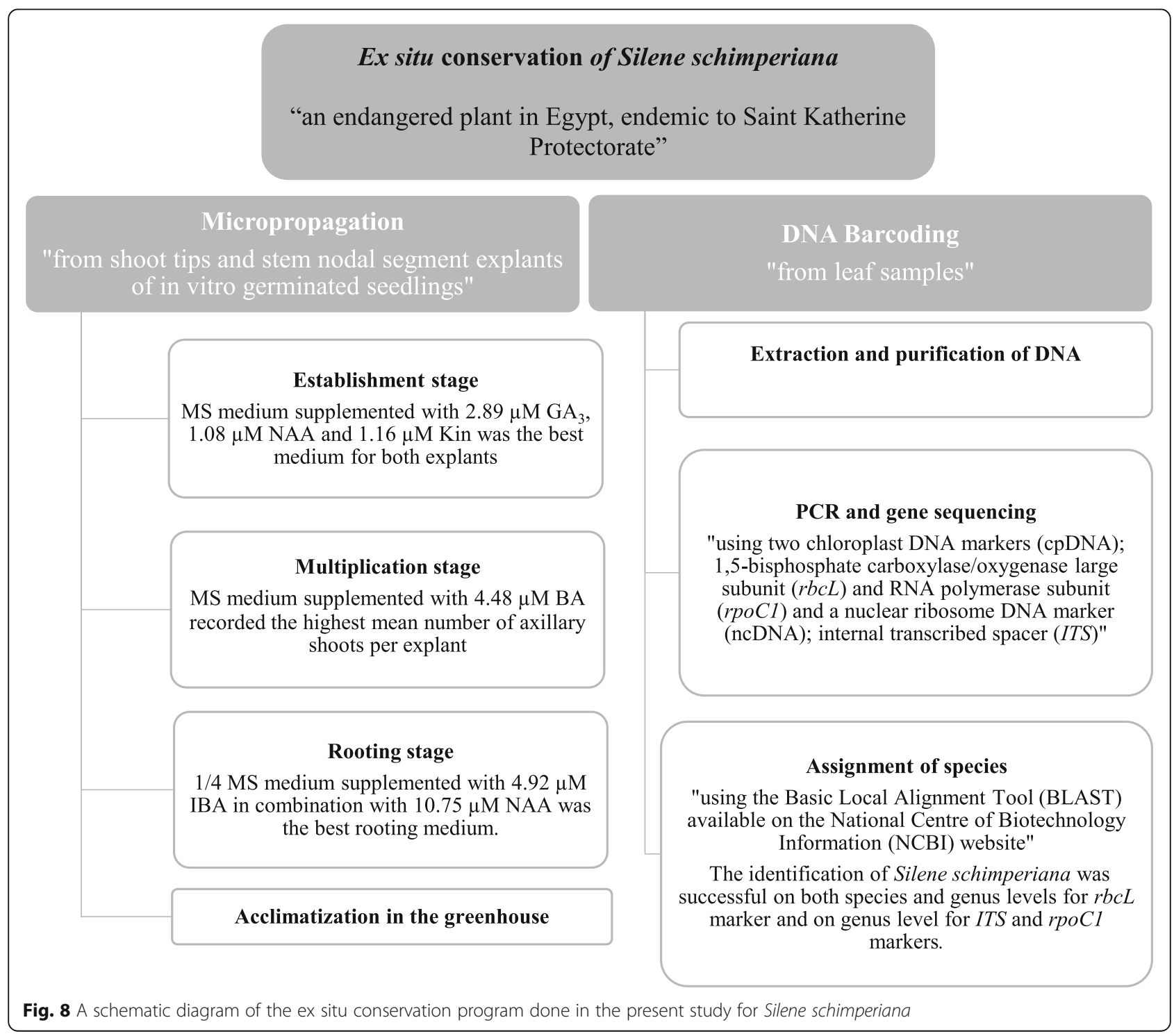




\section{Abbreviations}

ANOVA: Analysis of variance; BA: 6-benzyl adenine; BLAST: Basic local alignment tool; $\mathrm{CBOL}$ : Consortium for the barcode of life; CPDNA: Chloroplast DNA; GA spacer; 2iP: N6-(2-isopentenyl) adenine; IUCN: International Union for Conservation of Nature; Kin: kinetin; MS: Murashige and Skoog; NAA: a-naphthaleneacetic acid; NCBI: National Center of Biotechnology Information; ncDNA: nuclear DNA; PGRs: Plant growth regulators; rbcL: ribulose-1,5bisphosphate carboxylase/oxygenase large subunit; rpoC1: RNA polymerase C1; TDZ: thidiazuron

\section{Acknowledgements}

The authors are thankful to Dr. Ibrahim Abdelrafee El Gamal, Nature Conservation Sector, Egyptian Environmental Affairs Agency, Southern Sinai, Egypt, for his help in collecting plant specimens.

\section{Authors' contributions}

HG did the in vitro propagation of the plant. Shl did the DNA barcoding and analysis. GhH put the plan of the in vitro propagation section, did the acquisition and analysis of data, has written the manuscript and substantively revised it, and corresponding the publication. All authors read and approved the final manuscript.

\section{Funding}

Not applicable

\section{Availability of data and materials}

All data generated or analyzed during this study are included in this published article.

\section{Ethics approval and consent to participate}

Not applicable

\section{Consent for publication}

Not applicable

\section{Competing interests}

The authors declare that they have no competing interests.

\section{Author details}

${ }^{1}$ Tissue Culture Unit, Department of Genetic Resources, Desert Research Center, 1 Mathaf El-Matareya Street, Cairo, El-Matareya 11357, Egypt.

${ }^{2}$ Agricultural Genetic Engineering Institute, Agricultural Research Center, Giza, Egypt.

\section{Received: 14 May 2020 Accepted: 13 July 2020}

Published online: 10 August 2020

\section{References}

1. Omar K, Khafagi O, Elkholy MA (2013) Geomatics and plant conservation: GIS for best conservation planning. Saarbrücken: LAP LAMBERT Academic Publishing $\mathrm{GmbH} \&$ Co. KG, p. 312

2. Serag MM, Moustafa AA, Qiqa SS (2018) Impact of climate change on surviving of Phlomis aurea as an endemic species growing in southern Sinai, Egypt. Catrina 17(1):29-35

3. Täckholm V (1974) Students' flora of Egypt, 2nd edn. Cairo University, Egypt, Beirut

4. El-Hadidi MN, Batanouny KH, Fahmy AG (1991) The Egyptian plant red data book, vol 1, Trees and Shrubs. Department of Botany, Faculty of Science, Cairo University, Egypt

5. Omar KA, Elgamal I, Shalof A, Mehana S, Abdelbaset F (2017) Communitybased 534 conservation of threatened plants Silene schimperiana, and Polygala sinaica in South Sinai, 535 Egypt. Final Project Report. The Ruffor Foundation, p. 92

6. Saker M, El-Demerdash M, Allam MA (2011) In vitro propagation and genetic characterization as effective tools for conservation of Silene leucophylla, grown in St. Katherine protected area, Sinai, Egypt. J Genet Eng Biotechnol 9:21-27

7. Umralina AR (2013) In vitro culture introduction of Silene genus of Caryophyllaceae family endemic species. KazNU Bull Biol 2(58):55-60
8. Kritskaya TA, Kashin AS, Spivak VA, Firstov VE (2016) Features of clonal micropropagation of Silene cretacea (Caryophyllaceae) in in vitro culture. Russ J Dev Biol 47(6):359-366

9. Cördük N, Yücel G, Akıncı N, Tuna M, Esen O (2018) In vitro propagation of Silene bolanthoides Quezel. Contandr \& Pamukc and assessment of genetic stability by flow cytometry. Arch Biol Sci 70(1):141-148

10. Sarropoulou V, Maloupa E (2019) Micropropagation and ex situ conservation of Silene fabaria (L.) Sm. In Sibth. \& Sm. Subsp. domokina greuter (Caryophyllaceae); an important endemic plant in Greece with medicinal and ornamental value. J Adv Biotechnol 8. doi.org/https://doi.org/10.24297/ jbt.v8i0.8062.

11. Ferreira PMA, Boldrini I (2011) Potential reflection on distinct ecological units in plant endemism categories. Conserv Biol 25(4):672-679

12. Saddhe AA, Kumar K (2018) DNA barcoding of plants: selection of core markers for taxonomic groups. Plant Sci Today 5(1):9-13

13. Fouad AS, Hafez RM, Hosni HA (2019) Authentication of three endemic species of the Caryophyllaceae from Sinai peninsula using DNA barcoding. Egypt J Bot 59(2)

14. Mishra P, Kumar A, Nagireddy A, Mani DN (2016) DNA barcoding: an efficient tool to overcome authentication challenges in the herbal market. Plant Biotechnol J 14(1):1-21

15. Dong W, Liu J, Yu J, Wang L, Zhou S (2012) Highly variable chloroplast markers for evaluating plant phylogeny at low taxonomic levels and for DNA barcoding. PLoS One 7(4):e35071

16. CBOL Plant Working Group (2009) A DNA barcode for land plants. Proc Natl Acad Sci U S A 106:12794-12797

17. Kesanakurti PR, Fazekas AJ, Burgess KS, Percy DM et al (2011) Spatial patterns of plant diversity below-ground as revealed by DNA barcoding. Mol Ecol 20:1289-1302

18. Kang Y, Deng Z, Zang R, Lon W (2017) DNA barcoding analysis and phylogenetic relationships of tree species in tropical cloud forests. Sci Rep 7:12564

19. China Plant Barcode of Life (BOL) Group, Li DZ, Gao LM, Li HT, Wang H, Ge $\mathrm{XJ}$ et al (2011) Comparative analysis of a large dataset indicates that internal transcribed spacer (ITS) should be incorporated into the core barcode for seed plants. Proc Natl Acad Sci U S A 108:19641-19646

20. de Groot GA, During HJ, Maas JW, Schneider H et al (2011) Use of rbcL and trnL-F as a two-locus DNA barcode for identification of NW-European ferns: an ecological perspective. PLoS One 6:e16371

21. Murashige T, Skoog FA (1962) Revised medium for rapid growth and bioassay with tobacco tissue culture. Physiol Plant 15:473-497

22. Duncan DB (1955) Multiple range and multiple " $F$ " test. Biometrics 11:1-42

23. Snedecor GW, Cochran WG (1990) Statistical methods, 8th edn. lowa State University Press, Ames, lowa, USA

24. Ibrahim SD, Adawy SS, Atia MAM, Alsamman AM, Mokhtar MM (2016) Genetic diversity, variety identification and gene detection in some Egyptian grape varieties by SSR and SCOT markers. Plant Omics 9(5):311-318

25. George EF, Hall MA, De Klerk GJ (2008) Plant growth regulators III: Gibberellins, ethylene, abscisic acid, their analogues and inhibitors; miscellaneous compounds. In: George EF, Hall MA, Klerk GJ (eds) Plant propagation by tissue culture, Vol. 1: The back-ground, $3^{\text {rd }}$ ed. Springer Netherlands, Dordrecht, pp 227-281

26. Don Palmer C, Keller WA (2010) Plant regeneration from petal explants of Hypericum perforatum L. Plant Cell Tiss Org 105:129-134

27. Lebedev V, Arkaev M, Dremova M, Pozdniakov I, Shestibratov K (2019) Effects of growth regulators and gelling agents on ex vitro rooting of raspberry. Plants 8(3):1-10

28. Arab MM, Yadollahi A, Shojaeiyan A, Shokri S, Ghojah SM (2014) Effects of nutrient media, different cytokinin types and their concentrations on in vitro multiplication of GXN15 (hybrid of almond × peach) vegetative rootstock. J Genet Eng Biotechnol 12(2):81-87

29. Van Staden J, Zazimalova E, George EF (2008) Plant growth regulators II: cytokinins, their analogues and antagonists. In: George EF, Hall MA, Klerk GJ (eds) Plant propagation by tissue culture, Vol. 1: The Background, $3^{\text {rd }}$ ed. Springer Netherlands, Dordrecht, pp 205-226

30. Zhang H, Horgan KJ, Reynolds PHS, Jameson PE (2010) 6-Benzyladenine metabolism during reinvigoration of mature Pinus radiata buds in vitro. Tree Physiol 30:514-526

31. Tsafouros A, Roussos PA (2019) First report of Krymsk 5 (cv. VSL 2) cherry rootstock in vitro propagation: studying the effect of cytokinins, auxins and endogenous sugars. Not Bot Horti Agrobo 47(1):152-161 
32. Deepa AV, Anju M, Dennis TT (2018) The applications of TDZ in medicinal plant tissue culture. In: Ahmad N, Faisal M (eds) Thidiazuron: from urea derivative to plant growth regulator. Springer, Singapore

33. Jack EM, Anatasova S, Verkleij JAC (2005) Callus induction and plant regeneration in the metallophyte Silene vulgaris (Caryophyllaceae). Plant Cell Tiss Org 80:25-31

34. Dolcet-Sanjuan R, Claveria E, Gruselle R, Meier-Dinkel A, Jay-Allemand C, Gaspar $T$ (2004) Practical factors controlling in vitro adventitious root formation from walnut shoot microcuttings. J Am Soc Hortic Sci 129:198-203

35. Raveendar S, Lee G, Lee KJ, Shin M, Kim SH, Lee J, Cho G, Hyun DY (2019) DNA barcoding for efficient identification of Triticum subspecies: evaluation of four candidate loci on phylogenetic relationships. Plant Breed Biotech 7(3):220-228

36. Amandita FY, Rembold K, Vornam B, Rahayu S, Siregar IZ, Kreft H, Finkeldey R (2019) DNA barcoding of flowering plants in Sumatra, Indonesia. Ecol Evol 9(4):1858-1868

37. Hosein FN, Austin N, Maharaj S, Johnson W, Rostant L, Ramdass AC, Rampersad SN (2017) Utility of DNA barcoding to identify rare endemic vascular plant species in Trinidad. Ecol Evol 7(18):7311-7333

\section{Publisher's Note}

Springer Nature remains neutral with regard to jurisdictional claims in published maps and institutional affiliations.

\section{Submit your manuscript to a SpringerOpen ${ }^{\circ}$ journal and benefit from:}

- Convenient online submission

- Rigorous peer review

- Open access: articles freely available online

- High visibility within the field

- Retaining the copyright to your article

Submit your next manuscript at $\boldsymbol{\nabla}$ springeropen.com 